\title{
Learning in Engineering Project Management Classes: Does Technology Matter?
}

\section{Dr. Long Duy Nguyen P.E., Florida Gulf Coast University}

Dr. Long Nguyen is an Associate Professor in the Department of Environmental and Civil Engineering at Florida Gulf Coast University (FGCU). Before joining FGCU, he was the deputy director of Tuan Le Construction and a lecturer at Ho Chi Minh City University of Technology (HCMUT). Prior to his tenure at HCMUT, he worked as a construction consultant at Jax Kneppers Associates, Inc. in Walnut Creek, CA. He is a professional engineer registered in California. He earned his B.Eng. in Civil Engineering from HCMUT in 1999, M.Eng. in Construction Engineering and Management from Asian Institute of Technology (AIT) in 2003, and M.S. and Ph.D. in Engineering - Civil and Environmental Engineering from the University of California, Berkeley in 2005 and 2007, respectively.

\section{Dr. Robert O’Neill P.E., Florida Gulf Coast University}

Dr. ROBERT (Bob) J. O'NEILL is a Professor in the Department of Environmental and Civil Engineering, U.A. Whitaker College of Engineering, Florida Gulf Coast University. He received a B.S. from the United States Military Academy in 1975, an M.S. in Structural Engineering and an M.S. in Geotechnical Engineering from Stanford University in 1984 and a Ph.D. in Structural Engineering from Kansas State University in 1993. Prior to his coming to FGCU he was a Professor of Engineering at Roger Williams University and an Associate Professor and Director of the Civil Engineering Analysis Group at the United States Military Academy. Dr. O' Neill is a retired Lieutenant Colonel, U.S. Army Corps of Engineers. He has been active at the national level with ASCE's Committee on Accreditation Operations (COAO),Technical Council on Computing and Information Technology (TCCIT), Committee on Faculty Development (CFD) and Excellence in Civil Engineering Education (ExCEEd) initiative. Dr. O'Neill is a licensed Professional Engineer in California, Florida, Nevada and Virginia. He is a senior civil engineering program evaluator for ABET. He is an American Society of Civil Engineering (ASCE) Fellow, a member of the American Society for Engineering Education (ASEE), and Phi Kappa Phi National Honor Society.

\section{Dr. Simeon J. Komisar, Florida Gulf Coast University}

Dr. Komisar is the Backe Chair and Program Director of Environmental Engineering at FGCU 


\title{
Learning in Engineering Project Management Classes: Does Technology Matter?
}

\begin{abstract}
Increasing the interest, attention and engagement of engineering students in learning engineering and construction project management is a genuine challenge. Appropriate use of educational technologies such as cloud-based student response systems (SRSs) may promote learning and excitement. While educational technologies were reported to improve the student perceptions of learning and sometimes student performance, whether the teaching activities themselves or technologies employed in such activities contribute to learning remains unsettled. This study aims at filling this gap in knowledge in the context of teaching engineering project management classes. To investigate the role of the cloud-based SRS as an educational technology, this study utilized two sections, one "control" and one "subject," of the same class in engineering project management taught by the same instructor for the same cohort. In both control and subject sections, in-class review activities were used in most of the sessions for students to assess their learning in the previous session. In the control class, students worked with paper and pencil for activities projected in PowerPoint slides. The instructor then called on students for their answers. In the subject class, the same activities were embedded in a cloud-based SRS to which students worked and interactively responded. The instructor followed up with solutions for the activities if necessary in both classes. The technology significantly increased the participation of students in the in-class review activities. However, no statistically significant difference was found in both perceived and actual learning between the two sections. For future implementation of the cloudbased SRSs, higher participation yielded from the technology can contribute to learning if inclass activities are more meaningfully designed and allocated.
\end{abstract}

\section{Introduction}

Increasing the interest, attention and engagement of engineering students in learning engineering and construction project management is a genuine challenge. Effective active learning approaches are able to tackle such challenges. Appropriate use of technology in these approaches may promote learning and excitement. Educational technologies such as cloud-based student response systems (SRS) were reported to improve the student perceptions of learning and instruction and sometimes student performance in previous studies, including those in engineering education ${ }^{1}$. However, whether the teaching activities themselves or technologies employed in such activities contribute to the student's perception of learning remains undetermined.

This study aims at filling this gap in knowledge in the context of teaching engineering project management classes. This course was chosen because two sections of the course were offered and taught by the same instructor in the same semester for the same cohort, which reduced variables that could have confounding effects on the student perception and learning between sections. In addition, engaging students in these types of classes is potentially more challenging as students often perceive it as not a "core" course in their engineering major". This study addresses the enduring question "does the use of recent educational technologies improve the engagement and learning of engineering students?" As an educational technology, a cloud-based student response system (SRS), Poll Everywhere, was the focus of the current study. 
Multiple definitions of learning have been proposed in literature. Bingham and Conner ${ }^{3}$ defined "learning as the transformative process of taking in information that - when internalized and mixed with what we have experience - changes what we know and builds on what we do. It's based on input, process, and reflection." Brown et al. ${ }^{4}$ defined learning as "acquiring knowledge and skills and having them readily available from memory so you can make sense of future problems and opportunities." Adopting these definitions and for the purpose and scope of this study, learning is defined as the process of acquiring knowledge and information and having them internalized so students can solve problems given in relevant assessments. Among the three basic stages of learning, including acquisition, maintenance and generalization ${ }^{5}$, this definition of learning and the scope of the current study concentrate on the first two stages. Finally, as a recent study found that students in active learning classrooms learned more but their perception of learning was lower than that of students in passive environments ${ }^{6}$, both perception of learning and actual learning were considered in this study. The acquisition stage was measured through students' perceptions while the maintenance stage was assessed through both perceived and actual learning.

\section{Recent Studies of the Cloud-Based SRSs in Engineering Education}

Studies on the use and impacts of traditional SRSs on learning are not new and in fact have been reported for a few decades. Similar studies about cloud-based SRSs have been conducted in the last ten years, if not earlier. Table 1 summarizes recent studies regarding the implementation of the cloud-based SRSs in engineering education. Most of these studies reported on students' perceptions and some faculty reflection and did not have a baseline or a control to compare with.

Table 1. Recent studies of SRSs in engineering education

\begin{tabular}{|c|c|c|}
\hline Course(s) & SRS & Brief Description \\
\hline Introductory Electric & Top Hat & Several multiple-choice questions were asked with \\
\hline Circuits $^{7}$ & Monocle & $\begin{array}{l}\text { 2-5 minutes allowed for response during each } \\
\text { lecture. }\end{array}$ \\
\hline Physics and Chemistry ${ }^{8}$ & Kahoot! & $\begin{array}{l}\text { No-stake quizzes with Kahoot! were used in an } \\
\text { engineering school for reinforcement of knowledge. }\end{array}$ \\
\hline Electromagnetics $^{9}$ & Kahoot! & $\begin{array}{l}\text { The Kahoot! response system was not well suited for } \\
\text { the tutorial presentations. }\end{array}$ \\
\hline Introductory computing & Poll & A strong positive response from students was found \\
\hline course $^{10}$ & Everywhere & $\begin{array}{l}\text { in a large introductory computing course for non- } \\
\text { computer science majors. }\end{array}$ \\
\hline Graphical & Poll & Students' conceptual understanding was improved \\
\hline $\begin{array}{l}\text { Communications, } \\
\text { Dynamics, and Control } \\
\text { System Design }\end{array}$ & Everywhere & from the poll questions to the exam questions. \\
\hline \multirow[t]{2}{*}{ Circuits $^{1}$} & Poll & Both faculty and students found the use of the Poll \\
\hline & Everywhere & Everywhere effective. \\
\hline Engineering Project & Poll & The implementation of the poll app helped \\
\hline Management ${ }^{2}$ & Everywhere & $\begin{array}{l}\text { identifying knowledge gaps, extra practice and } \\
\text { collaborative learning. }\end{array}$ \\
\hline
\end{tabular}


When a study had a control ${ }^{2}$, there were still many confounding variables. For example, once inclass activities were introduced and embedded with a SRS, the impact, if any, could be from the activities themselves as course materials and/or from the SRS as an educational technology. The similar situation was observed in the studies of active learning which used "different course materials for active versus passive instruction, potentially confounding the effect of pedagogy with that of course materials." 6 To separately assess the impact of the SRS as an educational technology, this study chose the same in-class review activities that were conducted with a common mean (i.e., projected from PowerPoint slides) in the control section and with the cloudbased SRS in the subject section.

\section{Materials and Methods}

To investigate the role of technology in students' perceptions of learning, this study utilized two sections of the same semester-long senior-level course in engineering project management taught by the same instructor in Fall 2019. Each section had 48 civil and environmental engineering students. One section was considered the "control" and the other was the "subject". Both sections were scheduled in the same classroom that followed the SCALE-UP (student-centered active learning environment for undergraduate programs) model and had two sessions per week on Tuesdays and Thursdays. Each session lasted 2 hours and 15 minutes, including a 15-minute break. The control section started at 8:00 am while the subject section started at 1:00 pm. The course content consisted of three parts: (i) project management concepts and cost estimating; (ii) project financial evaluation or engineering economy; and (iii) project scheduling and controls. As the summative assessments of these three parts, three exams included $10 \%-15 \%$ conceptual and $85 \%-90 \%$ quantitative material. Three quizzes were given between exams as formative assessments. The course also included two application projects, cost estimating/bidding and project scheduling.

Table 2 summarizes the enrollments in the two sections. The course is required for both civil and environmental engineering majors. Dual majors were those who intended to pursue the two majors. Although the majority was civil engineering in both sections, more environmental engineering and dual-major students were in the subject section (45.8\%) compared to the control section $(16.7 \%)$. The gender distribution was quite similar in these sections.

Table 2. Enrollment of the control and subject sections

\begin{tabular}{lccccc}
\hline Description & \multicolumn{2}{c}{ Students in the control section } & & \multicolumn{2}{c}{ Students in the subject section } \\
\cline { 2 - 3 } \cline { 5 - 6 } & Number & Percent & & Number & Percent \\
\hline Enrollment & 48 & $100 \%$ & & 48 & $100 \%$ \\
Major & & & & 26 & $54.2 \%$ \\
$\quad$ Civil & 40 & $83.3 \%$ & & 15 & $31.2 \%$ \\
$\quad$ Environmental & 6 & $12.5 \%$ & & 7 & $14.6 \%$ \\
$\quad$ Dual majors & 2 & $4.2 \%$ & & & \\
Gender & & & & 34 & $70.8 \%$ \\
$\quad$ Male & 38 & $79.2 \%$ & & 14 & $29.2 \%$ \\
$\quad$ Female & 10 & $20.8 \%$ & &
\end{tabular}

In both sections, in-class review activities were used in most of the sessions for students to practice and assess their learning in the previous session. These activities took between 10 and 25 minutes of the class time. Figure 1 illustrates an activity used in Lesson 23 to review the 
previous lesson. In the control section, students worked with paper and pencil for activities projected in PowerPoint slides (Figure 1a). The instructor then called on students for their answers. In the subject class, the same activities were embedded in a cloud-based SRS to which students worked and interactively responded (Figure 1b). The SRS displays the students' responses in real time. In both classes, the instructor followed up with solutions for the activities if necessary. The activities were created to assist both the students and the instructor in identifying any points of confusion or misconception in the previous sessions. Two hypotheses were proposed to address the question stated in the introduction:

- Students perceived more participation in in-class review activities with the use of the cloud-based SRS in the subject section (H1).

- $\quad$ There were significant differences in actual and perceived learning between the control and subject sections $(\mathrm{H} 2)$.

\section{Lesson 22 Review}

- What is the duration of the project?

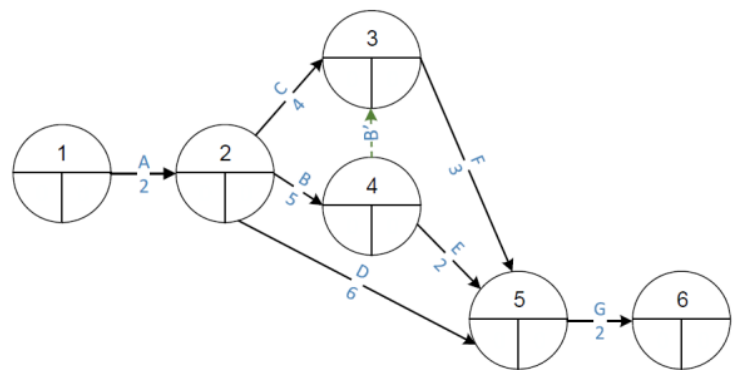

(a) Lesson 22 review activity in PowerPoint in the control section

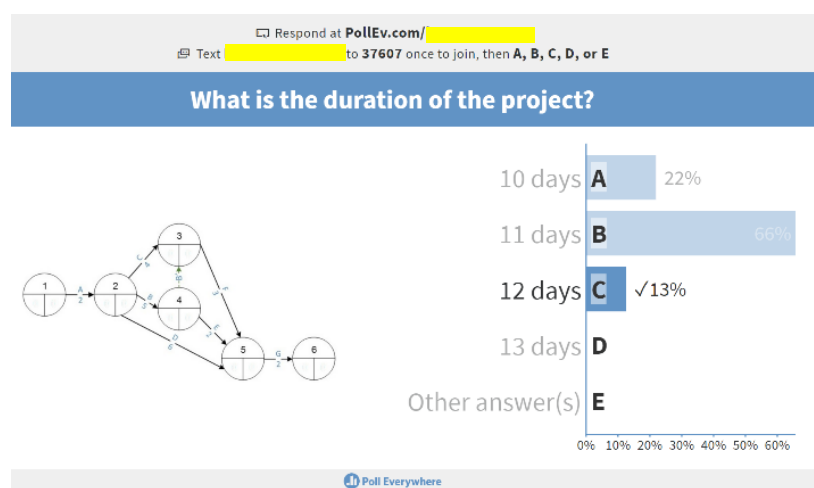

(b) Lesson 22 review activity in Poll Everywhere in the subject section

Figure 1. An example of in-class review activities in control and subject sections

Three data sources consisting of the official online student perception of instruction (SPoI) and paper-based surveys at the end of semester and summative assessments were collected and analyzed to evaluate and compare the perception and actual learning among engineering students in control and subject classes. The SPoI survey was embedded in the learning management system where students could respond anytime in the last three weeks of the semester and was used to collect the students' perceptions of the overall instruction of the course. In addition to the standard questions set up by the authors' institution, instructors are allowed to add up to five questions into the SPOI survey. As a result, two questions were added: (i) "what did you like most about the in-class review activities?" and (ii) "what did you like least about the in-class review activities?" in both control and subject sections. A paper-based survey was also conducted in class on the last day of the instruction. This survey had two main parts: (i) the selfassessment of student's ability to accomplish the course objectives and (ii) the use of in-class review activities. The summative assessments were the three exams given in the three parts of the course.

The valid response rates of the SPoI survey in the control and subject sections were $68.8 \%$ (33/48) and 56.3\% (27/48), respectively. The response rates of the paper-based survey were the 
same in two sections (46/48 or 95.8\%). The exam scores of all 96 students (48 in the control and 48 in the subject) were used to assess the actual learning. Descriptive statistics was mostly used for data analysis. When necessary, chi-square and two-sample t-tests were employed to test if there were any statistically significant differences between the control and subject sections. Specifically, a two-way chi-square test and two-sample t-tests were used to assess hypotheses H1 and $\mathrm{H} 2$, respectively.

\section{Results and Discussion}

\section{Tendency of Students' Perceptions of Instruction in the Control and Subject Classes}

Multiple factors may affect the interests, engagement, learning and then perception of a student on the course materials and instruction. For this study, student majors (e.g., more environmental and dual majors in the subject section) and time of day for class sessions (morning class vs. afternoon class) were two noticeable differences between the two sections. They were potentially confounding variables in this study. The student perception of overall instruction was first analyzed to assess the effect of these variables. Since the in-class review activities were accounted for a small portion of the class, they were expected to have a small impact on the student perception of the overall instruction.

Figure 2 displays the student perception of the overall instruction through four representative questions from the SPoI survey. These questions were rated in the five-point scale from "strongly disagree" (1) to "strongly agree" (5). The students in the subject section tended to rate 0.1 to 0.4 points lower on the overall instruction (Figure 2). This difference should be taken into consideration in the specific comparison of the in-class review activities in the control and subject sections.

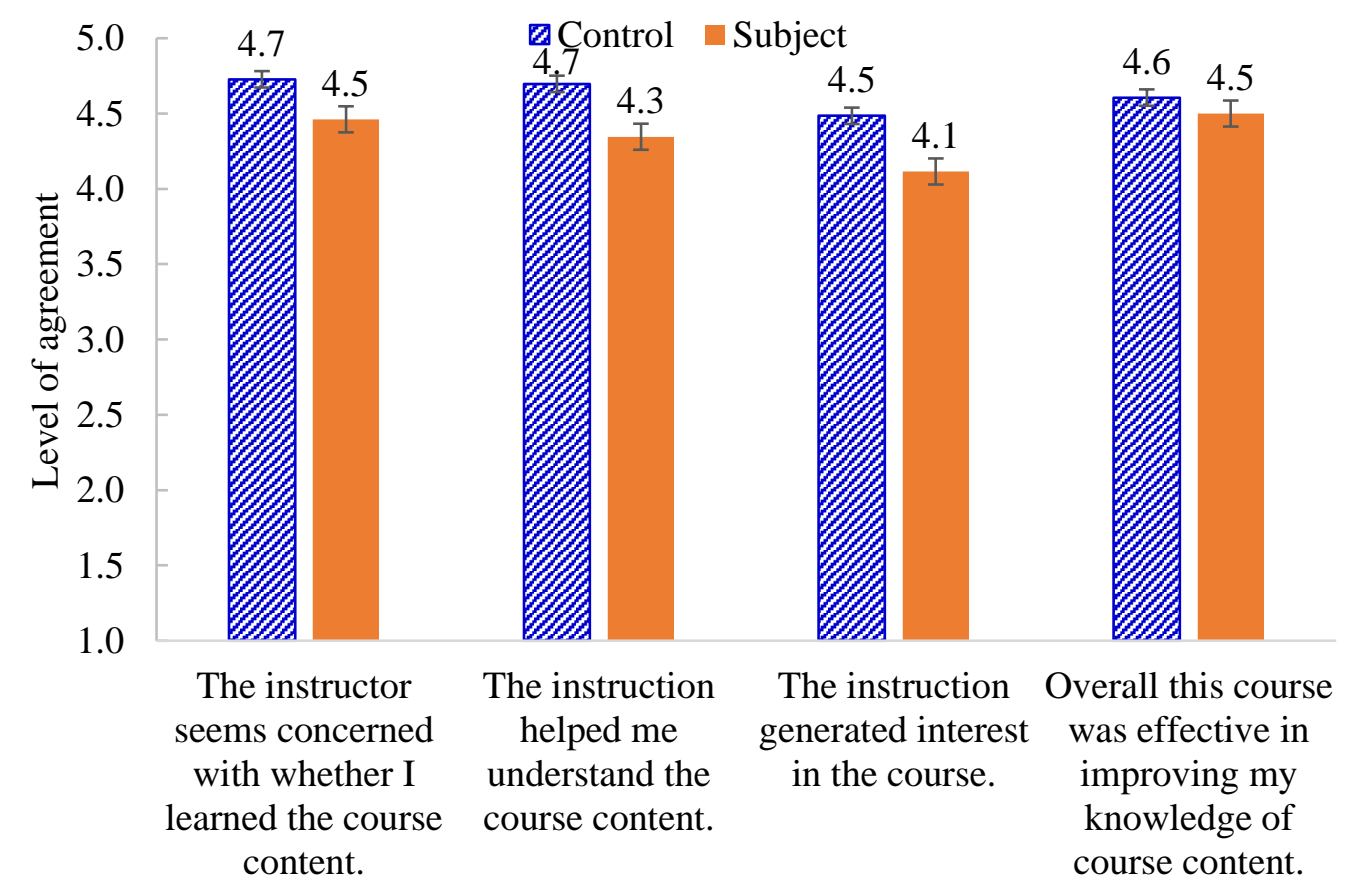

Figure 2. Student perception of overall instruction (error bars show one standard error) 


\section{Student Perception of the In-Class Review Activities with Different Uses of Technology}

Figure 3 displays the frequency of students working on in-class review activities in the control and subject sections. More than half (52\%) of the students in the subject section reported that they always worked on the in-class review activities while only one-fifth in the control section reported the same. In both sections, most of the students (96\%) at least sometimes participated in the activities. With two categorical variables, namely section (i.e., control and subject) and the frequency of students working in-class review activities (i.e., from "never" to "always"), a twoway chi-square test showed that the difference in participation between the control and subject sections was statistically significant $\left(\chi^{2}=17.1, p\right.$-value $\left.=0.002\right)$. Hypothesis $\mathrm{H} 1$ was therefore supported. Overall, the use of the cloud-based SRS increased the participation of the students in the corresponding activities. This was similar to the instructor's perspective in a previous study which stated stimulating students' participation was the major benefit of using Poll Everywhere ${ }^{5}$.

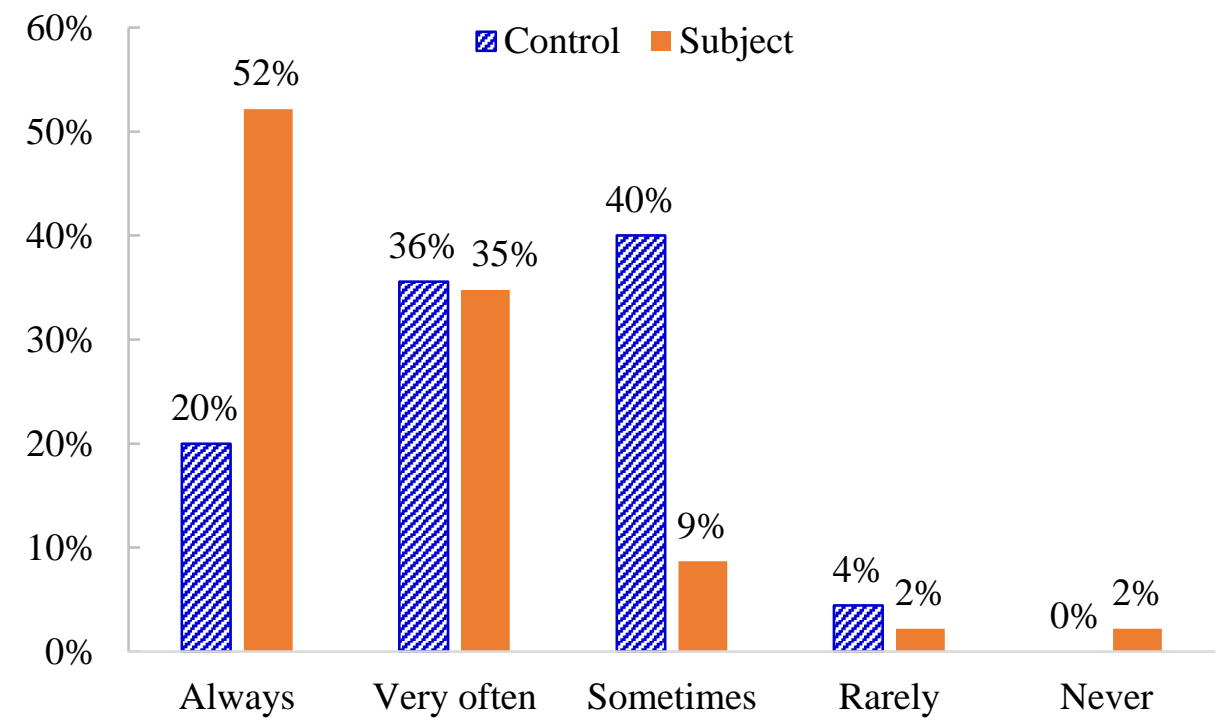

Figure 3. Frequency of students working on in-class review activities

The perception of engagement and interaction during the in-class review activities were compared between the control and subject sections. As in the SPoI, students were also asked in a five-point scale from "strongly disagree" (1) to "strongly agree" (5). As shown in Figure 4, students consistently rated lower in the subject section compared to the control section, i.e., from 0.1 to 0.5 lower. This difference was similar to the perception pattern of the overall instruction which students in the subject section tended to rate lower as discussed earlier (Figure 2).

Accounting for the confounding effect of the other factors (e.g., different proportions of majors, morning vs. afternoon sessions), there seemed to be no difference in terms of engagement and interaction or the process of acquiring knowledge between the control and subject sections during the in-class review activities, except the student interaction with the instructor. Students perceived less interaction with the instructor with the cloud-based SRS used in the subject section (Figure 4). This can be explained that with the interactive SRS, students were prone to focus more on responding to the activities through their electronic devices (i.e., phones, laptops) rather than on interacting with the instructor as in the paper and pencil in the control section. 
When using a cloud-based SRS, one should pay more attention to setting in-class activities that appropriately enhance the interaction between students and the instructor.

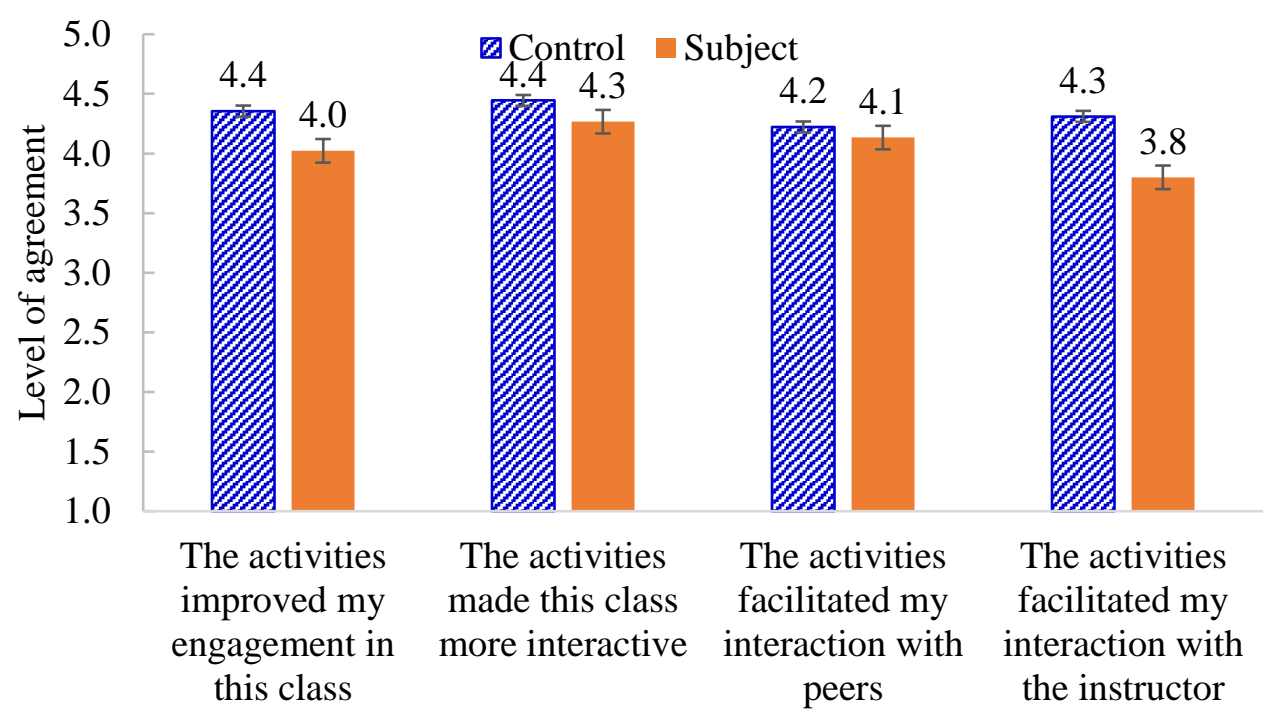

Figure 4. Student perception about engagement and interaction in the in-class review activities

In terms of how the in-class review activities helped the acquisition stage of learning, Figure 5 illustrates students' perceptions in the two sections. Similarly, students in the subject section consistently rated lower in comparison with the control section, i.e., from 0.4 to 0.7 point lower. Even considering the confounding effect that students in the subject section tended to rate 0.1 to 0.4 points lower as previously discussed, the perception of students about the in-class review activities embedded in the cloud-based SRS in the subject section was considerably lower in terms of preparation for quizzes and exams (the last two statements in Figure 5). One possible explanation could be the different forms of answers presented in several in-class review activities between the control and subject sections. For some quantitative problems as an example shown in Figure 1, the control section used open-ended (Figure 1a) while the subject section utilized multiple choice options available in the cloud-based SRS (Figure 1b) for the same activity. Since the open-ended questions were always used in the quizzes and exams, the students in the subject section may perceive lower contribution of the in-class review activities for their quizzes and exams. In addition, with multiple-choice settings some students might just guess an answer from the possible answers presented without working through the questions. 


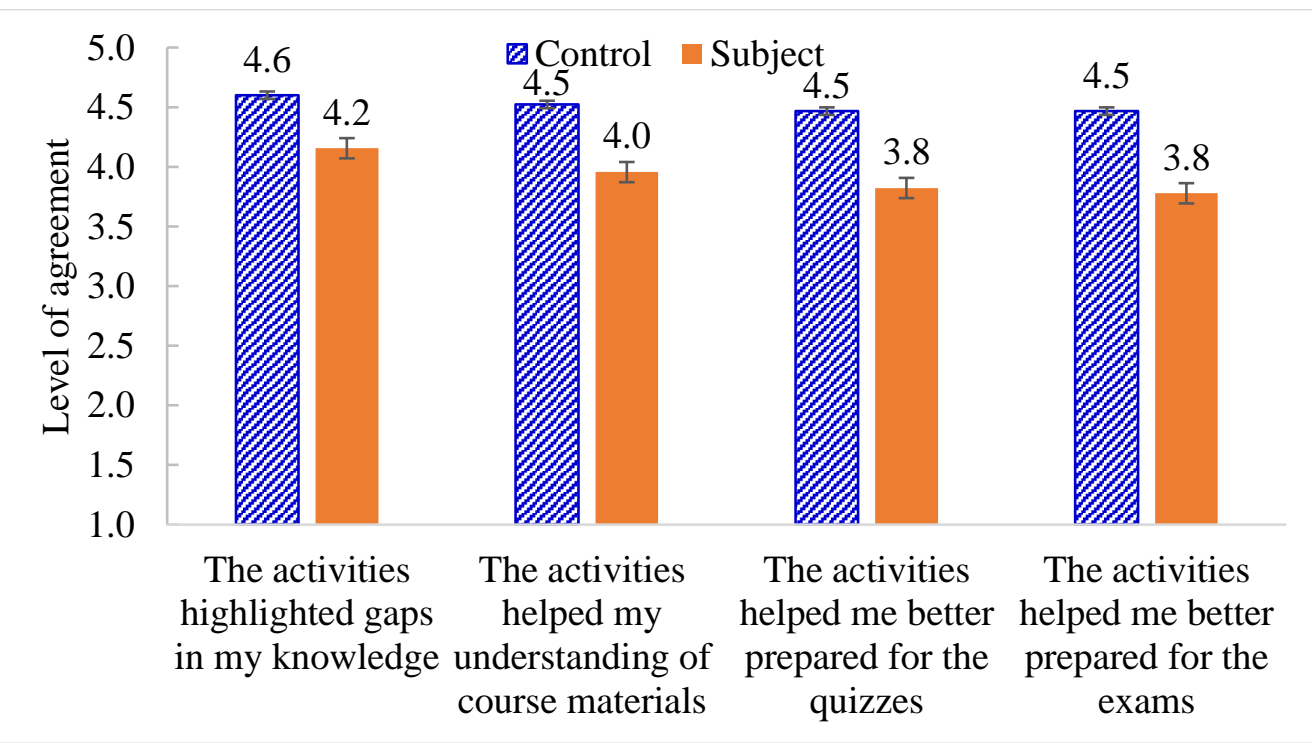

Figure 5. Student perception of knowledge acquisition in the in-class review activities

\section{Perceived Learning versus Actual Learning}

The maintenance stage of learning was assessed through the summative assessments and the students' self-assessments of the course objectives. Three summative assessments (i.e., exams) were used to assess each of the three parts of the course: (i) project management concepts and cost estimating; (ii) project financial evaluation or engineering economy; and (iii) project scheduling and controls. For the purpose of this study, only quantitative portions of these exams which accounted for $85-90 \%$ of total exam points were compared. In the paper-based survey, the students were also asked to self-assess their ability to accomplish the course objectives on the 4point scale, consisting of "unsatisfactory," "marginal," "satisfactory," and "excellent." Figure 6 summarizes the results of both faculty's assessment of learning and students' perceptions of learning in the three major knowledge areas covered in this course.

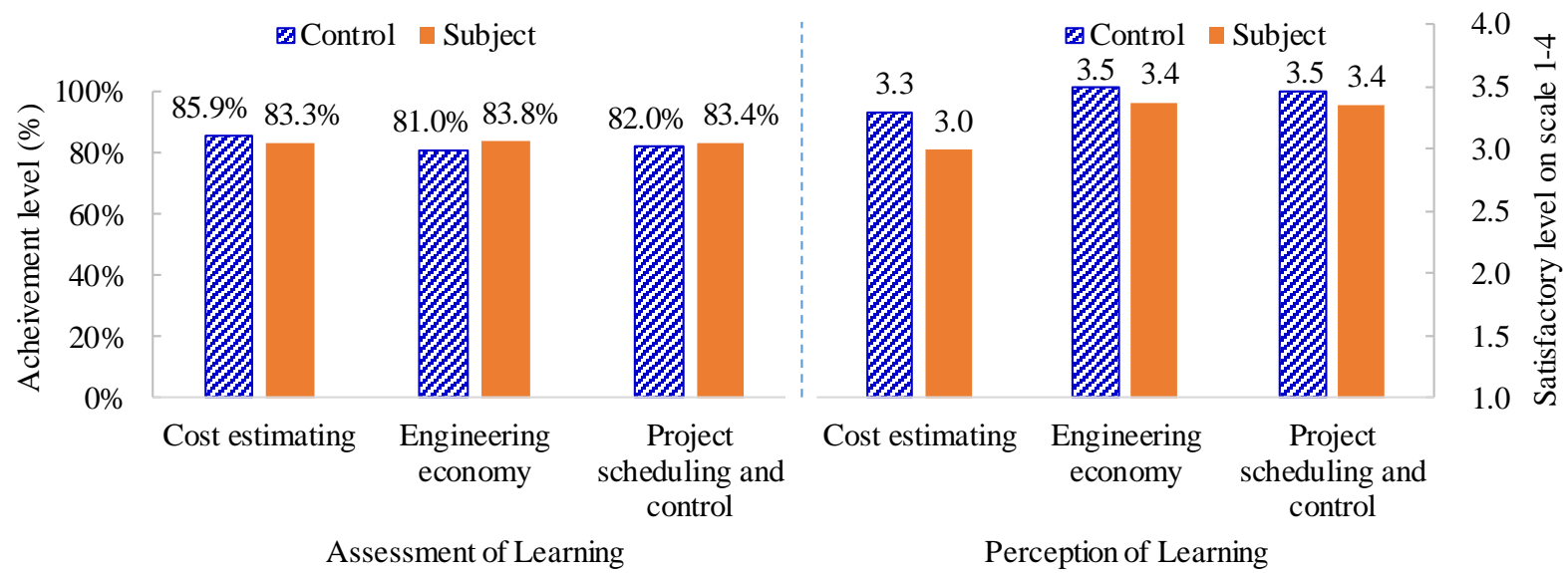

Figure 6. The maintenance stage of learning: actual versus perceived

The first three clustered columns in Figure 6 displays the achievement level (out of 100\%) in the summative assessments while the last three clustered columns showed the self-assessment of 
learning by students. For the self-assessment, students in the subject section rated lower with regard to their ability to accomplish the three knowledge areas. This was the same pattern as observed and discussed previously. In terms of actual learning, the achievement level of the subject section was higher in "engineering economy" (2.8\% higher) and "project scheduling and control" (1.4\% higher). The achievement level of "cost estimating" was however $2.6 \%$ lower in the subject section. The exam for cost estimating included a real-world engineering drawing where students were asked to read, take off quantities and estimate the costs. Although this course had two sessions for blueprint readings, students who had prior knowledge of blueprints could have some advantage in cost estimating. As a related knowledge, "Engineering Computer Graphics" where students learned drawing in AutoCAD and Civil 3D was a sophomore-level course required for the civil engineering major only. Higher proportion of the environmental engineering majors who had less or no prior knowledge of drawings in the subject section could somewhat explain the lower achievement level in cost estimating in this section. The students' self-assessment also reflected this lower achievement level of cost estimating in the subject section that rated 0.3 point lower in cost estimating while rated only 0.1 point lower in the other two knowledge areas (Figure 6).

When there was no advantage of prior knowledge due to differences of course requirements by majors such as engineering economy and project scheduling and control, the achievement level was higher in the subject section. The higher achievement level in the subject section could come from many factors that were not considered in the current study, e.g., student's academic ability and performance, time to study for the exams, deadlines and requirements of other courses prior to, on and right after the exam dates of this course. Therefore, it was premature to attribute the higher achievement level for the use of the more recent technology (i.e., the cloud-based SRS) in the subject section. Nevertheless, two-sample t-tests showed that the differences in the achievement level were not statistically significant: $p$-values $=0.157,0.101$ and 0.471 for cost estimating, engineering economy, and project planning and control, respectively (Table 3 ). Hypothesis H2 was therefore not supported.

Table 3. Summary of t-tests on actual learning

\begin{tabular}{lcccccc}
\hline \multirow{2}{*}{ Description } & \multicolumn{2}{c}{ Cost estimating } & \multicolumn{2}{c}{ Engineering economy } & \multicolumn{2}{c}{ Scheduling/control } \\
\cline { 2 - 7 } & Control & Subject & Control & Subject & Control & Subject \\
\hline Mean & 0.859 & 0.833 & 0.810 & 0.838 & 0.820 & 0.834 \\
Variance & 0.007 & 0.008 & 0.006 & 0.008 & 0.008 & 0.009 \\
Observations & 48 & 48 & 48 & 48 & 48 & 48 \\
t-statistic & \multicolumn{2}{c}{1.427} & \multicolumn{2}{c}{-1.654} & \multicolumn{2}{c}{-0.724} \\
p-value (two-tailed) & \multicolumn{2}{c}{0.157} & \multicolumn{2}{c}{0.101} & \multicolumn{2}{c}{0.471} \\
\hline
\end{tabular}

\section{Conclusions and Limitations}

This study explored the effects of a cloud-based SRS as an educational technology on student engagement and learning. The technology significantly increased the participation of students in the in-class review activities. However, it did not change the students' perceptions of engagement and interaction in the SCALE-UP classrooms, except that interaction with the instructor appeared to be perceived less in the review activities in the subject section. There was also no difference in the students' perceptions of the knowledge acquisition. In terms of the maintenance of knowledge, after the effect of confounding variables was considered, the perceived learning was similar while the actual learning appeared to be higher in the subject 
section. The difference was however not statistically significant. In sum, the implementation of the cloud-based SRS in the current study made no significant difference in improving the acquisition and maintenance stages of learning in the engineering project management class.

Regardless, one major positive implication of the educational technology can be drawn from this study. The results showed the increased student participation of the in-class review activities with the cloud-based SRS. As such, if in-class activities are more appropriately designed for all stages of learning, the higher meaningful participation from students, instead of just hitting an answer shown on phone screens that may happen to some students, can lead to higher achievement. The future implementation of the educational technology can focus on utilizing the positive participation to boost student learning.

Despite attempting to avoid shortcomings in the previous studies, the current study still has limitations. The fact that the potential benefits of the cloud-based SRS were not realized may be because the in-class review activities took a small portion of class sessions, especially when other active learning methods were also implemented in both control and subject sections. The choice of the control and subject classes while yielding many of the same conditions there still existed variances (class time of the day, distribution of majors, level of participation in some inclass review activities that had different answer settings, etc.) which may have had confounding impacts on the results. The authors intend to flip control and subject sections in the next offering to understand the effect of these variances. Finally, this study did not account for other important variables such as students' past performance and time outside of class dedicated for studying the course materials.

\section{References}

${ }^{1}$ Sun, L. and Tang, Y. "Enhancing conceptual understanding by using a real-time online class response system in engineering courses." Proceedings of the ASEE $122^{\text {nd }}$ Annual Conference and Exposition, Seattle, WA, June 14-17, 2015.

${ }^{2}$ Nguyen, L. D., O’Neill, R. J., and Komisar, S. J. “Using poll app to improve active learning in an engineering project management course offered to civil and environmental engineering students." Proceedings of the ASEE $126^{\text {th }}$ Annual Conference and Exposition, Tampa, FL, June 16-19, 2019.

${ }^{3}$ Bingham, T., and Conner, M. The new social learning: A guide to transforming organizations through social media. Berrett-Koehler Publishers, San Francisco, CA, 2010

${ }^{4}$ Brown, P. C., Roediger III, H. L. and McDaniel, M. A. Make it stick: The science of successful learning. Harvard University Press, Cambridge, MA, 2014.

${ }^{5}$ Popescu, O., Chezan, L. C., Jovanovic,. V. M. and Ayala, O. M. "The use of Polleverywhere in engineering technology classes to stimulate student critical thinking and motivation."

Proceedings of the ASEE 122 ${ }^{\text {nd }}$ Annual Conference and Exposition, Seattle, WA, June 14-17, 2015.

${ }^{6}$ Deslauriers, L., McCarty, L. S., Miller, K., Callaghan, K., and Kestin, G. "Measuring actual learning versus feeling of learning in response to being actively engaged in the classroom." Proceedings of the National Academy of Sciences, 116(39), 19251-19257, 2019.

${ }^{7}$ Dunning, S. "Evaluation of an interactive classroom tool applied in an introductory electric circuits course." Proceedings of the ASEE $121^{\text {st }}$ Annual Conference and Exposition, Indianapolis, IN, June 15-18, 2014. 
${ }^{8}$ Cutri, R., Marim, L.R., Cordeiro, J.R., Gil, H.A.C. and Guerald, C.C.T. "Kahoot, a new and cheap way to get classroom-response instead of using clickers." Proceedings of the ASEE $123^{\text {rd }}$ Annual Conference and Exposition, New Orleans, LA, June 26-29, 2016.

${ }^{9}$ Young, M. G., Conry, J. P., Greco, E. C. "Implementation of electrostatics tutorials utilizing an electronic response system." Proceedings of the ASEE $125^{\text {th }}$ Annual Conference and Exposition, Salt Lake City, UT, June 24-27, 2018.

${ }^{10}$ Kappers, W. M. and Cutler, S. L. "Poll Everywhere! Even in the classroom: An investigation into the impact of using PollEverwhere in a large-lecture classroom." Computers in Education Journal, 6(20), 140-145, 2015. 